\title{
Happy and successful 2003!
}

\section{J R Kalden, L B A van de Putte}

\section{Your journal and society continue to grow}

$\mathrm{T}$ his year the Annals enters its fourth year as the official journal of the European League Against Rheumatism, EULAR; in this role the journal flourishes. In the past few years the number of manuscripts submitted has almost doubled, the circulation quadrupled, and the impact of the journal increased considerably.

The editorial team was proud to learn that so many readers appreciated the change and (as they described it) improvement in the design of the journal. The readership may have noticed that since July 2002 the procedures leading to publication have become totally electronic. This means that the whole process-namely, submitting a manuscript, manuscript review, decision making, and editing, is now electronic, and therefore faster than before. Although, inevitably, there have been minor starting problems (which have been largely solved), the new system has been received enthusiastically by an impressive majority of authors, reviewers, and others involved in the publication process. We, the editorial team, backed by strong support from the BMJ Publishing Group, will continue to improve the system.

In 2002 two new associate editors joined the team, Professor Frank Wollheim from Lund and Professor Bevrah Hahn from Los Angeles. The board welcomes these colleagues for their specific expertise and thanks them for their willingness to participate.

In addition to recent expansion of the EULAR journal, EULAR itself has developed over the past few years. The annual conference, which started in Nice three years ago, has become an international annual event with attendees from all over the world. The number of participants registering increases each year, with more than 8000 in Stockholm in June this year.

EULAR has also significantly enlarged its educational activities. Thus, a visiting professor programme, EULAR training bursaries, and travel bursaries enabling young rheumatologists to attend the annual conference have been established. The successful postgraduate courses will be continued and expanded.

Finally, EULAR has established a research grant, which will support collaborative research between European rheumatology groups in fields that are in line with the goals and strategies of EULAR.

On behalf of EULAR, and its official journal, the Annals of the Rheumatic Diseases, we wish you a happy, fruitful, and prosperous 2003.

Ann Rheum Dis 2003;62:1

\section{Authors' affiliations}

J R Kalden, President of EULAR

L B A van de Putte, Editor in chief of the Annals

\section{Defective waste disposal: does it induce autoantibodies in SLE?}

\section{P J Charles}

\section{Considerable evidence points to a dysregulated or dysfunctional clearance of apoptotic cells in human SLE}

A poptosis, or programmed cell death is central in the normal physiological function of multicellular organisms and is implicated in developmental and homoeostatic mechanisms. It is a complex process that seeks to limit the ability for cellular constituents to leak from a cell and cause damage to surrounding tissues, and to prevent intracellular material from being recognised by the immune system. Phagocytosis of apoptotic cells is critical in their disposal and occurs before membrane degradation, thus ensuring the rapid and safe elimination of potentially inflammatory or immunogenic material from the circulation.

Since the pioneering work by Rosen and colleagues first demonstrated that an autoantigen associated with systemic rheumatic diseases could be located in the blebs of apoptotic cells, ${ }^{1}$ there has been a growing interest in the role of apoptosis in the production of autoantibodies. It has subsequently been shown that many such autoantigens can be found in macromolecular structures in cell surface vesicles during apoptosis. ${ }^{23}$ These possess the antigenic determinants that bind to autoantibodies from patients with a variety of autoimmune diseases. ${ }^{45}$ However, it must be appreciated that because apoptosis is a normal physiological event, exposure to potential autoantigens is likely to be common in healthy subjects without the induction of autoimmunity. As more is understood about the process of apoptosis, the potential for dysregulation at multiple levels leading to the induction of autoimmune diseases is suggested (fig l). It is likely that further research will uncover more of these links.

One area of research which has attracted interest is concerned with the mechanisms of clearance from the circulation of antigenic material generated by apoptosis. Under normal circumstances any material that escapes clearance by phagocytosis can be rapidly cleared from the circulation by a number of additional mechanisms. These include binding by proteins such as $\mathrm{C}$ reactive protein (CRP) or Clq, or by antibodies to form immune complexes (reviewed by Navratil and Ahearn $^{6}$ ). These antigen-protein complexes are then actively removed from the circulation. van Nieuwenhuijze and colleagues in this issue have suggested another mechanism that limits the intracellular material released. ${ }^{7}$ They report that cells undergoing apoptosis only release low levels of nucleosomes during the first 24 hours following induction of apoptosis by etopiside or by anti-CD95 monoclonal antibodies. This provides an opportunity for efficient clearance by macrophage phagocytosis and therefore a limited release of potentially autoantigenic material. They then go onto discuss the potential that a faulty mechanism may potentiate autoimmunity in systemic lupus erythematosus (SLE) and other autoimmune diseases by increasing the rate of antigenic release, leading to an increased load of nucleosomal antigen, which may in turn lead to a 
MECHANISM INDUCTION
SIGNALING
PATHWAYS

APOPTOSIS

\section{CLEARANCE} MECHANISMS

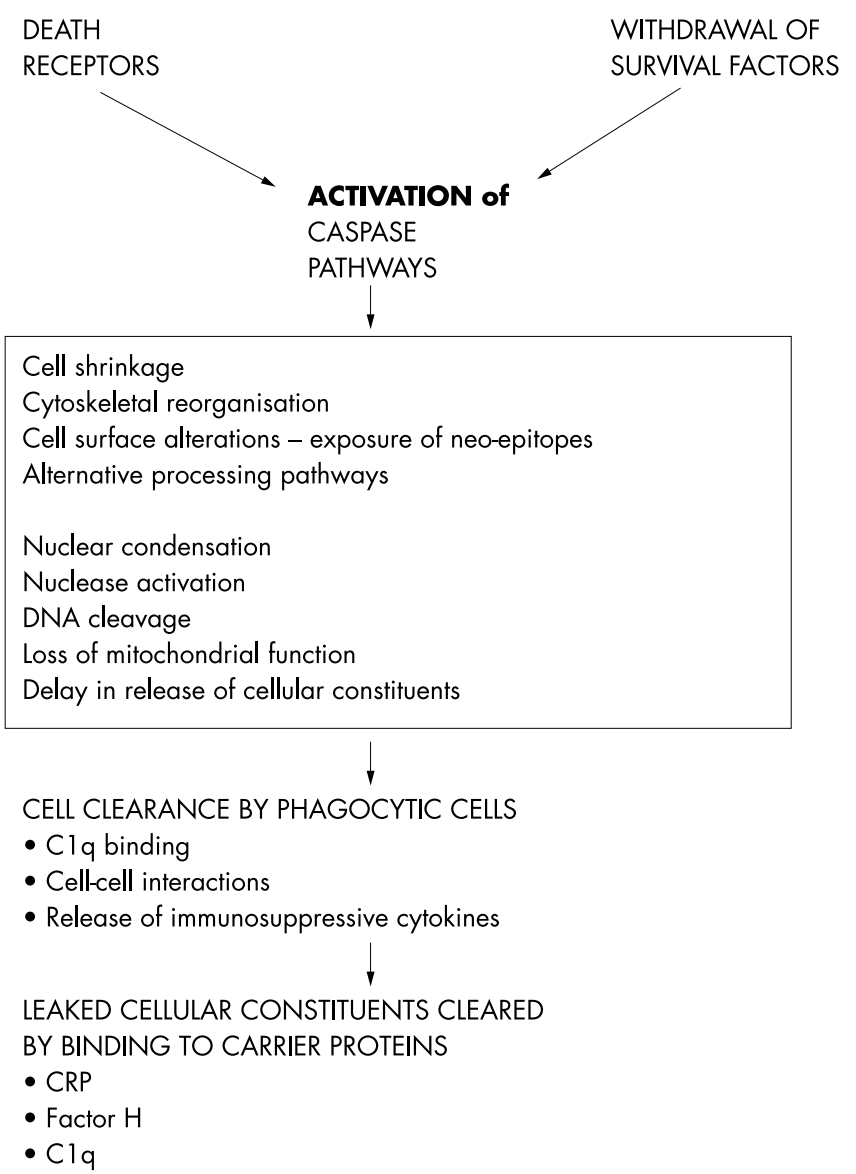

\section{DISEASE}

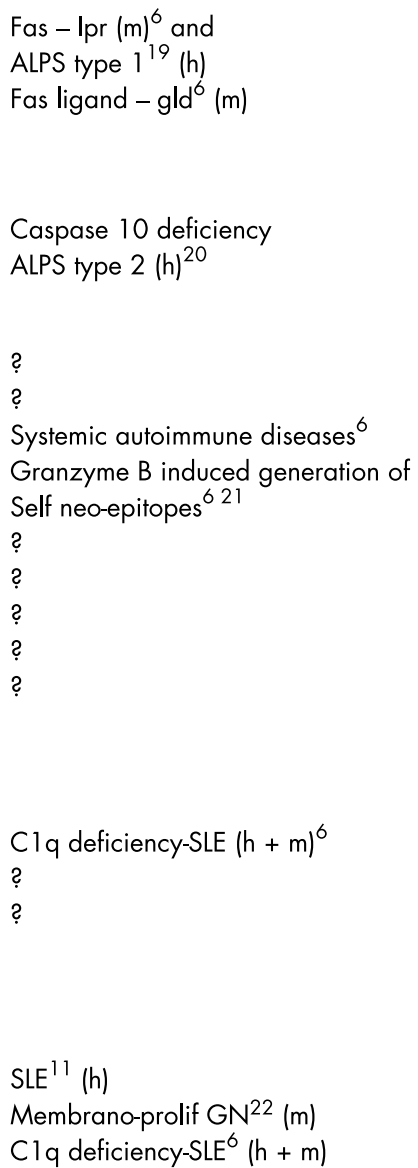

Figure 1 The process of apoptosis and the potential points in that process at which deficiency or mutations may lead to the induction of autoimmune diseases. ? indicates no autoimmune induction currently identified with this mechanism; ALPS, autoimmune lymphoproliferative syndrome; (h), human; (m), marine.

diversion of processing from macrophages to professional antigen presenting cells, such as dendritic cells.

$$
\begin{aligned}
& \text { "Generation of autoantibodies } \\
& \text { does not itself lead to the } \\
& \text { development of SLE" }
\end{aligned}
$$

Animal models have begun to identify some of the important molecules in the clearance of potentially antigenic material from the circulation. DNase I knockout mice develop a lupus-like disease with antinuclear antibodies and an immune nephritis. ${ }^{8}$ DNase I is an enzyme responsible for the degradation of DNA in nuclear antigens, and thus its absence prevents part of the degradative process, leading to the safe handling of antigens containing DNA. Similar phenotypes have also been reported for the SAP and Clq knockout mice, and both of these molecules are thought to be important in the clearance of potential autoantigens..$^{69^{10}}$ The administration of CRP to NZB $\times N Z W$ Fl mice has been shown to reduce autoantibody levels and to prolong survival. ${ }^{11}$ All these models provide evidence that these complex mechanisms evolved to prevent the interaction of the immune system with the products of apoptosis. This defective clearance results in the high levels of free nucleosomal antigens present in the circulation of MRL/lpr mice. ${ }^{12}$ But is there any evidence that these mechanisms are defective in human SLE?

Defective Fc dependent clearance of immune complexes has been reported. Davies and colleagues have shown that in patients with SLE, immune complexes are taken up and processed by the liver. ${ }^{13}$ However, this processing is only partial, and partially degraded, and potentially immunogenic, immune complex material is rapidly released back into the circulation. The same author has also shown that the splenic uptake and retention of immune complexes is abnormal in patients with SLE. ${ }^{14}$ de la Fuente and colleagues have reported abnormalities of phagocyte function in patients with lupus, ${ }^{15}$ and this may account for the inefficient processing of immune complexes observed by Davies and colleagues. Baumann and coworkers have reported increased numbers of apoptotic cells, together with decreased numbers of macrophages, in lymph nodes taken from patients with SLE, ${ }^{16}$ indicating a delay in the clearance of these dying cells. The presence of free circulating nucleosomes and antinucleosome antibodies in the circulation of these patients has also been reported. ${ }^{17}$ All this evidence points to a dysregulated or dysfunctional clearance of apoptotic cells in human SLE.

Further evidence that the removal of apoptotic material is abnormal in patients with SLE can be indirectly drawn from the association between deficiencies of the classical pathway of complement and the occurrence of SLE (reviewed by Navratil and Ahearn ${ }^{6}$ ). Evidence from both human and murine studies has identified Clq as important molecules in the clearance of apoptotic material. ${ }^{10}$ Thus, it would seem likely that in the absence of one or more of these components antigenic clearance is delayed, autoantigens are processed by the immune system, and autoantibodies are generated. It is important, however, to recognise that the generation of autoantibodies does not itself lead to the development of SLE. In a recent study we reported on 22 patients with rheumatoid arthritis who developed anti-dsDNA 
antibodies after treatment with infliximab, however, only one of these developed clinical symptoms of $\mathrm{SLE}^{18}$ and therefore other risk factors must also be important in the development of an autoimmune disease.

When looking at the documented clearance abnormalities described in either murine or human lupus, it is clear that there are a number of different abnormalities seen in different patients, leading to a similar defect-that is, the defective clearance of apoptotic material. A question that needs to be answered is why the apparent redundancy in the systems does not cancel out a single abnormality? Even in the closely studied cases of complement deficiency, there is not a 100\% occurrence of SLE. This suggests that there may be a need for more than one abnormality to be present in order for clinical disease to occur. The concept of multiple susceptibility genes contributing to a single clinical phenotype has been suggested from previous genetic studies of SLE and other autoimmune diseases. If this is the case there is a need for studies looking at multiple clearance mechanisms to examine the coexistence of these features in patients with SLE. It may be found from such studies that specific autoimmune or clinical profiles are related to specific molecular defects.

To this we can now add another mechanism that has the potential to be defective. If, as the evidence suggests, apoptosis is accelerated in SLE, then it may be that there are abnormalities within the delay mechanism described by van Nieuwenhuijze and colleagues. It is likely that any such abnormality would lead to a lack of control of early antigenic release. This would result in the release of large quantities of antigenic material into a circulation already struggling to cope with antigenic overload, and would lead to the initiation of the immune system, autoantibodies and, should other risk factors be present, to clinical lupus. In a patient with established lupus, this defect would continue to fuel the fire. We await the results of future studies to provide the answers.

Ann Rheum Dis 2003;62:1-3

\section{Authors' affiliations}

P J Charles, Kennedy Institute of Rheumatology Division, Imperial college of Science, Technology and Medicine, and Division of Immunology, Hammersmith Hospitals NHS Trust, London, W6 8RF, UK

Correspondence to: Dr P J Charles; peter.charles@ic.ac.uk

\section{REFERENCES}

1 Casciola-Rosen LA, Anhalt G, Rosen A Autoantigens targeted in systemic lupus erythaematosus are clustered in two populations of surface structures on apoptotic keratinocytes. J Exp Med 1994;179:131730.

2 Rosen A, Casciola-Rosen LA. Autoantigens as substrates for apoptotic proteases: implications for the pathogenesis of systemic autoimmune disease. Cell Death and Differentiation 1999:6:6-12.

3 Huggins ML, Todd I, Cavers MA, Pavulur SR, Tighe PJ, Powell RJ. Antibodies from systemic lupus erythaematosus (SLE) sera define differential release of autoantigens from cell lines undergoing apoptosis. Clin Exp Immunol 1999; 1 18:322-8.

4 Griedinger EL, Casciola-Rosen L, Morris SM, Hoffman RW, Rosen A. Autoantibody recognition of distinctly modified forms of the U1-70-kd antigen is associated with different clinical disease manifestations. Arthritis Rheum 2000;43:881-8.

5 Mevorach D, Zhpou JL, Song X, Elkon KB. Systemic exposure to irradiated apoptotic cells induces autoantibody induction. J Exp Med 1998; 188387-92.

6 Navratil JS, Ahearn JM. Apoptosis, clearance mechanisms, and the development of systemic lupus erythematosus. Current Rheumatol Rep 2001;3:191-8.

7 van Nieuwenhuijze AEM, van Lopik T, Smeenk RJT, Aarden LA. Time between onset of apoptosis and release of nucleosomes from apoptotic cells: putative implications for systemic lupus erythematosus. Ann Rheum Dis 2003;62:10-14.

8 Napirei $M$, Karsunky H, Zevnik B, Stephan H, Mannherz HG, Moroy T. Features of systemic lupus erythematosus in Dnase 1-deficient mice. Nat Genet 2000;25:177-81.

9 Bickerstaff MC, Botto M, Hutchinson WL, Herbert J, Tennant GA, Bybee A, et al. Serum amyloid $P$ component controls chromatin degredation and prevents antinuclear autoimmunity. Nat Med 1999;5:852-3.

10 Mitchell DA, Pickering MC, Warren J, Fossati-Jimack L, Cortes-Hernandez J, Cook M, et al. $\mathrm{Clq}$ deficiency and autoimmunity: the effects of genetic background on disease expression. J Immunol 2002; 168:2538-43.

11 Du Clos TW, Zlock LT, Hicks PS, Mold C. Decreased autoantibody levels and enhanced survival of (NZBxNZW) mice treated with C-reactive protein. Clin Immunol Immunopathol 1994:70:22-7.

12 Licht R, van Bruggen MC, Oppers-Walgreen B, Rijke TP, Berden JH. Plasma levels of nucleosome and nucleosome-autoantibody complexes in murine lupus: effects of disease progression and lipopolysaccharide administration. Arthritis Rheum 2001:44:1320-30.

13 Davies KA, Robson MG, Peters AM Norsworthy P, Nash JT, Walport MÁ Defective Fc-dependent processing of immune complexes in patients with systemic lupus erythematosus. Arthritis Rheum 2002;46:1028-38

14 Davies KA, Peters AM, Beynon HL, Walport MA. Immune complex processing in patients with systemic lupus erythematosus. In vivo imaging and clearance studies. J Clin Invest 1992;90:2075-83.

15 de la Fuente $\mathbf{H}$, Richaud-Patin $Y$, Jakez-Ocampo J, Gonzalez-Amaro R, Liorente $L$. Inate immune mechanisms in the pathogenesis of systemic lupus erythematosus. pathogenesis of systemic lupus eryt
Immunol Lett 2001;77:175-80.

16 Baumann I, Kolowos W, Voll RE, Manger B, Gaipl U, Neuhuber WL, et al. Impaired uptake of apoptotic cells into tingible body macrophages in germinal centres of patients with systemic lupus erythematosus. Arthritis wheum 200;46:191-201.

17 Amoura Z, Piette JC, Chabre H, Cacoub H, Cacoub P, Papo T, et al. B. Circulating plasma levels of nucleosomes in patients with systemic lupus erythematosus: correlation with serum antinucleosome antibody titers and absence of clear association with disease absence of clear association with disease
activity. Arthritis Rheum 1997;40:2217-25.

18 Charles PJ, Smeenk RJT, Dejong J, Feldmann $M$, Maini RN. Antibodies to dsDNA induced in RA following treatment with a monoclonal antibody to TNF. Arthritis Rheum 2000;43:2883-900.

19 Martin DA, Zheng L, Siegel RM, Huang B, Fisher $\mathrm{GH}$, Wang J, et al. Defective CD95/APO-1/Fas signal complex formation in the human autoimmune lymphoproliferative syndrome, type 1a. Proc Natl Acad Sci USA 1999:96:4552-7.

20 Wang J, Zheng L, Lobitto A, Chan FK, Dale J, Sneller $M$, et al. Inherited human caspase 10 deficiency mutations underlie defective lymphocyte and dendritic cell apoptosis in autoimmune lymphoproliferative syndrome type II. Cell 1999:98:47-58.

21 Casciola-Rosen L, Andrade F, Ulanet D Wong WB, Rosen A. Cleavage by granzyme $B$ is strongly predictive of autoantigen status: implications for the initiation of

autoimmunnity. J Exp Med 199; 190:815-26.

22 Pickering MC, Cook HT, Warren J, Bygrave AE, Moss J, Walport M, et al. Uncontrolled C3 activation causes membranoproliferative glomerulonephritis in mice deficient in complement factor H. Nat Genet 2002:July 1 (e-pub ahead of print). 